line is that the academic boycott (such as it was) was more a nuisance than an effective agent for change in South Africa, in part because many of the restrictions were, in fact, quite easy to get around. (An exception was copies of dissertations, which UMI refused to supply.) A most interesting work. (SL)

Building Partnerships: Computing and Library Professionals. Ed. Anne Lipow and Sheila Creth. Berkeley, Calif.: Library Solutions Pr., 1995. 102p. \$29, paper. (ISBN 1-882208-18-8.)

The papers in this volume were presented at a two-day program designed to bring together librarians and computing professionals to talk about how to work collaboratively in new ways. The goal was to explore common interests and acknowledge the real differences of perspective. Clearly, the increasing interdependency of libraries and campus computing centers is uncomfortable for both sides. The resulting book is useful but very tentative - mostly affirmations of the importance (and difficulties) of collaboration with brief descriptions of nine specific collaborative projects underway at various campuses. Perhaps most useful is the more extended paper tracing the recent history of computing/library interaction at Rice University. $(B W)$

Contributed by Stephen Lehmann, Bob Walther, and Ethelene Whitmire.

\title{
Use INTERNET to
}

\section{UnCover...}

\section{UnCover}

6 million articles from 20,000 multidisciplinary periodicals delivered by fax in 24 hours or less

UnCover
Reveal
Electronic TOC
service with
user profiling

UnCover Complete

Pre-1989 journals can be ordered online

\section{UnCover SOS \\ Order articles by fax, phone, e-mail or post from UnCover's Single Order Source service}

\section{The UnCover Company}

E-mail: uncover@carl.org

380 I East Florida Avenue, Suite 200 a Denver, CO 80210, USA

Phone: 1-800-787-7979 ם Fax: 303-758-5946

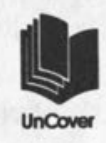

Readmore, Inc. 22 Cortlandt Street New York, NY 10007 ...Articles Phone: I-800-221-3306

UnCover is a service of Readmore, Inc. 